\title{
Bariatric surgery in an aging population: what is an appropriate preoperative workup?
}

\author{
Abbreviations: ACC: American College of Cardiology; CAD: \\ Coronary Artery Disease; AHA: American Heart Association; RCRI: \\ Revised Cardiac Risk Index; EKG: Electrocardiogram;
}

\section{Editorial}

According to the United States Census Bureau, 14.1\% of the United States population is over the age of 65. Since the 1900's this population has grown from 3million to 40million in 2010. By 2030 this population is projected to almost double to 72 million and account for almost $20 \%$ of the population. ${ }^{1}$ With an expanding population over the age of 65 there will be an increasing obese population within this subset. According to the U.S. Department of Health and Human Services, the rate of the obese population over the age of 65 has increased from $22 \%$ in $1988-1994$ to $38 \%$ in $2010-2011 .^{2}$ With the positive outcomes of bariatric surgery, we should expect to see more patients over the age of 65 seeking bariatric surgery. There have been multiple studies ${ }^{3-9}$ that have shown that bariatric surgery is safe above the age of 65 and even 70years old. Our question is what is the appropriate work up for an aging population to ensure the best outcomes in this population.

Age alone has never been found to be an absolute contraindication to surgery, especially bariatric surgery. ${ }^{6,7}$ Bariatric surgery is an elective procedure that should be performed with the surgeon's expertise and judgment to have the final say over who can undergo surgery. ${ }^{10}$ From a cardiac risk standpoint, age alone has also not been found to be an independent predictor of morbidity or mortality. ${ }^{11,12}$

Mortality from non-cardiac surgery has been well studied in the current medical literature. In a study from Jin et al. ${ }^{13}$ the overall mortality rate among the general population for all non-cardiac surgery was $1.2 \%$. When looking at specific age ranges, this increases to $2.2 \%$ in patients $60-69$ years old, $2.9 \%$ in patients $70-79$ years old, $5.8-6.2 \%$ in patients $>80$ years old and $8.4 \%$ in patients $>90$ years old. This was further expanded to look at specifically patients with coronary artery disease (CAD). They found that there was a $4.1 \%$ incidence of perioperative MI and 5.5\% rate of reinfarction the patient was over the age of 65 . This was compared to the general population less than $65 y e a r s$ old at $3.5-4.2 \%$ for reinfarction. ${ }^{13}$ The American College of Cardiology (ACC) and American Heart Association (AHA) classify intraperitoneal surgery as intermediate risk with a cardiac risk of surgery alone of $>1 \%$ but $<5 \%$. $^{14}$

Kheterpal et al. ${ }^{15}$ in 2009 found that age was an independent risk factor for a cardiac adverse event after non-cardiac surgery. They found a $1.1 \%$ risk for a cardiac adverse event for all non-cardiac operations performed within a 30 day post operative period. Nine independent risk factors were identified including age $>68$ years old, BMI $>/ 30$, emergent surgery, previous coronary intervention or cardiac surgery, active congestive heart failure, cerebrovascular disease, hypertension, operation $>/ 3.8$ hours and the administration of 1 or more units of packed red blood cells intraoperatively. ${ }^{15}$

The original Goldman cardiac risk score included age $>70$ as a risk factor with a value of 5 points. Intraperitoneal surgery is given

\author{
Volume 2 Issue 2 - 2015
jill Gorsuch, Flavia C Soto, Albert Chen, Emil Graf, David Podkameni \\ Bariatric Center, Banner Health, US
}

\author{
Correspondence: Flavia C Soto, Bariatric Center, Banner \\ Health, Higley Road and US 60 Higley Road Gilbert, Arizona \\ 85234, US, Tel 9545992153. \\ Email Flavia.Soto@bannerhealth.com
}

Received: January 31, 2015 | Published: February 14, 2015

a score of 3 points. ${ }^{16}$ Just those two factors alone on this scale would place a patient with no other risk factors with a score of 8 and a risk of major cardiac event at $9 \%$. This has since been updated by Lee et al. ${ }^{17}$ to the Revised Cardiac Risk Index (RCRI). ${ }^{17}$ This scale was validated in patients over the age of 50years old, but age is not included as a specific risk factor. If only looking at the risk of the surgical procedure of 1 point on the scale, this places bariatric surgery as an RCRI class II and a $1 \%$ overall risk for a cardiac event. ${ }^{17}$ One limit of the RCRI is the fact that it better predicts cardiac events in patients $<55$ years old. ${ }^{18}$ This limits the ability to extrapolate the overall risk factors and appropriate work up outlined by the RCRI and the need to create an independent risk stratification that can be utilized in the elderly population.

Lee et al. ${ }^{17}$ recommended a preoperative EGK and chest x-ray for RCRI class II. ${ }^{17,18}$ Intermediate risk per RCRI would then include lipid lowering agents, tight blood pressure control and no clear recommendation for the addition of noninvasive stress testing. High risk RSRI or signs and symptoms of coronary artery disease should include diagnostic catheterization with revascularization if needed. Special attention should be made to the diabetic population. More aggressive testing should be carried out including electrocardiogram (EKG), noninvasive stress test and close monitoring of creatinine level. ${ }^{19}$

There have been several studies looking at overall complications among the bariatric population, but not specifically at cardiac complications and what preoperative work up would be appropriate to predict a worse outcome after surgery. There are two studies that document male patients and higher weight at time of surgery were independent risk factors to overall complications after surgery. Livingston et al. ${ }^{20}$ also found in their study that morbidity rate was the same within their young and older population, but those patients greater than 55years old had a three fold increase in mortality rate relative to the younger patients. ${ }^{20}$

Obesity has been documented as a major modifiable risk factor for coronary heart disease, ventricular dysfunction, left ventricular hypertrophy, poor left ventricular systolic function and impairment of left ventricular diastolic function, congestive heart failure, stroke and cardiac arrhythmia by the AHA. It is believed that physical exam and EKG alone can underestimate the presence and extent of cardiac disease in the obese patient. ${ }^{10,21-24}$ Subtle EKG changes that are 
nonspecific but can be found within the obese population due to body habitus changes of the diaphragm include may lead to an extensive cardiac workup. Echocardiogam can also lead to both false positive and false negative exams with an obese body habitus. Overall, nuclear perfusion scans have been shown effective in the obese population. ${ }^{25-27}$

Our biggest challenge as bariatric surgeons before surgery is to identify the severely obese patient who is at higher perioperative cardiovascular risk. ${ }^{28}$ The physical examination solo underestimates cardiac dysfunction most of the time in this patient population. The obtainment of a12-lead ECG and a chest radiograph is reasonable in all elderly severely obese patients under consideration for surgery, but sometimes not enough. It is our recommendation, based on our practice experience, to add a dobutamine stress test to those that have history of metabolic syndrome, strong cardiac family history and those who present with abnormal base line testing (EKG, Chest X ray, etc). Abnormal results should be address by the cardiologist for potential indication of coronary catheterization and treatment.

Cardiac symptoms such as exertional dyspnea and lower-extremity edema are nonspecific in obesity. The severely obese patient with poor functional capacity should receive careful clinical evaluation. We should also remember that patients with BMI of 40 or more correlate with higher incidence of cardiomyopathy. In the end in Bariatric Surgery, it is all about safety.

\section{Acknowledgements}

None.

\section{Conflict of interest}

The author declares no conflict of interest

\section{References}

1. Bureau US. United States Census Bureau. State and Country Quick Facts. 2013.

2. US Department of Health and Human Services. Federal report details health, economic status of older Americans. National Institute of Aging; 2012.

3. Ramirez AR, Roy M, Hidalgo JE, et al. Outcomes of bariatric surgery in patients > 70years old. Surg Obes Relat Dis. 2012;8(4):458-462.

4. Willkomm CF, Fisher TL, Barnes GS, et al. Surgical weight loss $>65$ years old:is it worth the risk? Surg Obes Relat Dis. 2010;6(5):491-496.

5. Spaniolas KT, Trus TL, Adrales GL, et al. Early morbidity and mortality of laparoscopic sleeve gastrectomy and gastric bypass in the elderly:a NSQIP analysis. Surg Obes Relat Dis. 2014;10(4):584-588.

6. Dorman RB, Abraham AA, Al-Refaie WB, et al. Bariatric Surgery Outcomes in the Elderly:An ACS NSQIP Study. $J$ Gastrointest Surg. 2012;16(1):35-44.

7. Qin C, Luo B, Aggarwal A, et al. Advanced Age as an Independent Predictor of Perioperative Risk after Laparoscopic Sleeve Gastrectomy. Obes Surg. 2015;25(3):406-412.

8. Varela JW, Wilson SE, Nguyen NT. Outcomes of Bariatric Surgery in the Elderly. Am Surg. 2006;72(10):865-869.

9. Soto Flavia C, Gari V, De la Garza J, et al. Sleeve gastrectomy in elderly: A safe and effective procedure with minimal morbidity and mortality. Obes Surg. 2013;23(9):1445-1449.

10. Koruda MS, Sheldon GF. Surgery in the aged. Adv Surg. 1991;24:239331.
11. Sieber FB, Barnett SR. Preventing Postoperative Complications in the Elderly. Anesthesiol Clin. 2011;29(1):83-97.

12. Ramesh HB, Boase T, Audisio RA. Risk Assessment for Cancer Surgery in Elderly Patients. Clin Interv Aging. 2006;1(3):221-227.

13. Jin F, Chung F. Minimizing Perioperative Adverse Events in the Elderly. Br J Anaesth. 2001;87(4):608-624.

14. Eagle KB, Berger PB, Calkins H, et al. American College of Cardiology; American Heart Association:ACC/AHA guideline update for perioperative cardiovascular evaluation for noncardiac surger-executive summary:A Report of the American College of Cardiology/American Heart Assocaition Task Force on Practice Guidelines. J Am Coll Cardiol. 2002;39(3):542-553.

15. Kheterpal S, Reilly OM, Englesbe MJ, et al. Preoperative and intraoperative predictors of cardiac events after general, vascular and urological surgery. Anesthesiology. 2009;110(1):58-66.

16. Goldman LC, Caldera DL, Nussbaum SR, et al. Multifactorial index of cardiac risk in noncardiac surgical patients. $N$ Engl $J$ Med. 1977;297(16):845-850.

17. Lee TM, Marcantonio ER, Mangione CM, et al. Derivation and prospective validation of a simple index for prediction of cardiac risk of major noncardiac surgery. Circulation. 1999;100(10):1043-1049.

18. Grasso AW, Wael AJ. Cardiac Risk Stratification for Noncardiac Surgery. Cleveland Clinic Center for Continuing Education; 2015.

19. Mason EE, Renquist KE, Jiang D. Preopearive Risks and Safety of Surgery for Severe Obesity. Am J Clin Nutr. 1992;55(2):5735-5765.

20. Livingston EH, Huerta S, Arthur D, et al. Male Gender is a Predictor of Morbidity and Age is a Predictor of Mortality for Patients Undergoing Gastric Bypass Surgery. Ann Surg. 2002;236(5):576-582.

21. Eckel RK, Krauss RM. American Heart Association Call to Action:Obesity as a Major Risk Factor for Coronary Heart Disease. AHA Nutrition Committee. Circulation. 1998;97(21):2099-2100.

22. Klein S, Burke LE, Bray GA, et al. Clinical Implications of Obesity with Specific Focus on Cardiovascular Disease:a statement for professionals from the American Heart Association Council on Nutrition, Physical Activity, and Metabolism:endorsed by the American College of Cardiology Foundation. Circulation. 2004;110(18):2952-2967.

23. Poirier P, Alpert MA, Fleisher LA, et al. Cardiovascular Evaluation and Management of Severely Obese Patients Undergoing Surgery:a science advisory from the American Heart Association. Circulation. 2009;120(1):86-95.

24. Poirier P, Cornier MA, Mazzone T, et al. Bariatric Surgery and Cardiovascular Risk Factors:a scientific statement from the American Heart Association. Circulation. 2011;123(15):1683-1701.

25. Poirier P, Giles TD, Bray GA, et al. Obesity and Cardiovascular Disease:Pathophysiology, Evaluation and Effect of Weight Loss :an update of the 1997 American Heart Association Scientific Statement on Obesity and Heart Disease from the Obesity Committee of the Council on Nutrition, Physical Activity, and Metabolism. Circulation. 2006;113(6):898-918.

26. Blankstein R. Can Advances in Nuclear Cardiolgy Hardware Overcome the Challenges of Imaging Obese Patients? J Nucl Cardiol. 2015;22(2):276-278.

27. Gugliotti D, Grant P, Jaber W, et al. Challenges in Cardiac Risk Assessment in Bariatric Surgery Patients. Obes Surg. 2008;18(1):129133.

28. Katkhouda NM, Mason RJ, Wu B, et al. Evaluation and treatment of patients with cardiac disease undergoing bariatric surgery. Surg Obes Relat Dis. 2012;8(5):634-640. 